\title{
Voltage Stabilization of a Wind Turbine with STATCOM Using Intelligent Control Techniques
}

\author{
SA Gawish, SM Sharaf, MS EI-Harony \\ Department of Electrical Power and Machines Engineering, Faculty of Engineering of Helwan, \\ University of Helwan
}

\begin{abstract}
Application of FACTS controller called Static Synchronous Compensator STATCOM to improve the performance of power grid with Wind System is investigated. The essential feature of the STATCOM is that it has the ability to absorb or inject fastly reactive power with power grid. Therefore the voltage regulation of the power grid with STATCOM FACTS device is achieved. Moreover restoring the stability of the wind system at suddenly step up or down in wind speed is obtained with STATCOM. This paper describes a complete simulation of voltage regulation of a wind system using STATCOM. Conventional control technique as proportional plus integral controller and intelligent techniques as FLC and ANFIS are used in this work. The control technique is performed using MATLAB package software. The dynamic response of uncontrolled system is also investigated under wide range of disturbances. The voltage regulation by using STATCOM whose output is varied so as to maintain or control output voltage in the system. The dynamic response of controlled system is shown and comparison between the uncontrolled system and the controlled system is described to assure the validity of the proposed controller. Also comparison between the proposed control methods scheme is presented. To validate the powerful of the STATCOM FACTS controllers, the studied power system is simulated and subjected to different severe disturbances. The results prove the effectiveness of the proposed STATCOM controller in terms of fast damping the power system oscillations and restoring the power system stability and voltage.
\end{abstract}

Keywords: wind system; STATCOM; Voltage stabilization; PI controller; fuzzy logic controller, ANFIS controller

\section{Introduction}

Global warming is one of the most serious environmental problems facing the world community today. It is typified by increasing the average temperature of Earth's surface and extremes of weather both hot and cold. Therefore, implementing smart and renewable energies such as wind power, photo voltaic etc, are expected to deeply reduce heat-trapping emissions. Moreover, wind power is expected to be economically attractive when the wind speed of the proposed site is considerable for electrical generation and electric energy is not easily available from the grid [1]. This situation is usually found on islands and/or in remote localities. However, wind power is intermittent due to worst case weather conditions such as an extended period of overcast skies or when there is no wind for several weeks. As a result, wind power generation is variable and unpredictable. The wind power with rectifier and inverter generation has been suggested $[2,3]$ to handle the problem above. Wind system with STATCOM is very reliable because the STATCOM acts as a cushion to take care of variation in wind speed and would always maintain an average voltage equal to the set point. However, in addition to the unsteady nature of wind, another serious problem faced by the isolated power generation is the frequent change in load demands. This may cause large and severe oscillation of power. The fluctuation of output power of such renewable sources may cause a serious problem of frequency and voltage fluctuation of the grid, especially, in the case of isolated microgrid, which is the a small power supply network consisting of some renewable sources and loads. In the worst case, the system may lose stability if the system frequency can not be maintained in the acceptable range.

Control schemes to enhance stability in a wind -system have been proposed by much researchers in the previous work. The programmed pitch controller (PPC) in the wind side can be expected to be a cost-effective device for reducing frequency deviation $[4,5]$. Nevertheless, under the sudden change of load demands and random wind power input, the pitch controller of the wind side able to effectively control the system frequency due to theirs slow response. 
FACTS devices can be a solution to these problems [6]. They are able to provide rapid active and reactive power compensations to power systems, and therefore can be used to provide voltage support and power flow control, increase transient stability and improve power oscillation damping. Suitably located FACTS devices allow more efficient utilization of existing transmission networks. Among the FACTS family, the shunt FACTS devices such as the STATCOM has been widely used to provide smooth and rapid steady state and transient voltage control at points in the network. In this paper, a STATCOM is added to the power network to provide dynamic voltage control for the wind system, dynamic power flow control for the transmission lines, relieve transmission congestion and improve power oscillation damping.

Traditional optimization methods such as mixed integer linear and non linear programming have been investigated to address this issue; however difficulties arise due to multiple local minima and overwhelming computational effort. In order to overcome these problems, Evolutionary Computation Techniques have been employed to solve the optimal parameters of FACTS devices. Fuzzy logic controller (FLC) [11, 12], is an evolutionary computation technique that has been applied to other power engineering problems, giving better results than classical techniques and with less computational effort. In this paper the gains of the controllers with STATCOM have been optimized and optimum transient by trial and error it using to determine the optimal parameters of the PI controller in STATCOM such as PI controller in AC voltage regulator, DC voltage regulator. Simulation results show that the STATCOM devices significantly improve the performance of the wind with rectifier and inverter system, and the grid during transient disturbances.

\section{Wind Energy System with STATCOM}

Figure 1 presents a schematic diagram of a generalized wind system with STATCOM. The model represents the wind turbine, and the generator (three phase permanent magnet synchronous generator). The PMSG generator is connected in parallel rectifier, inverter, and connected to STATCOM and the utility grid through transmission line.

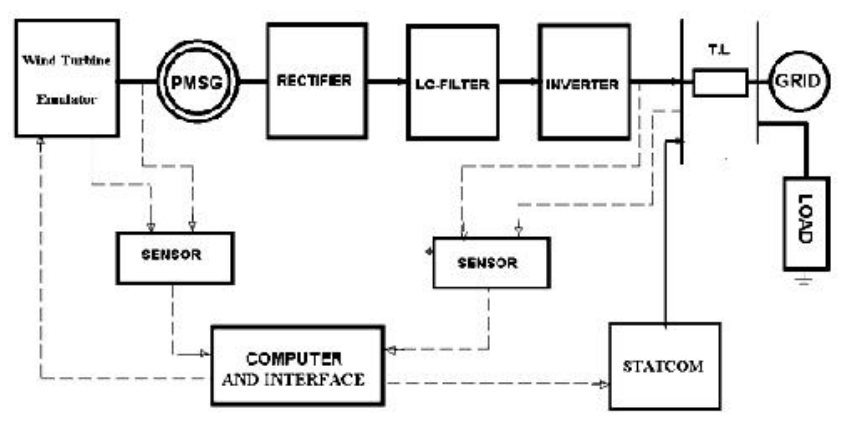

Figure 1. Wind system with STATCOM

\section{Mathematical Model of the System}

The active power feed to the grid is fulfilled by the permanent magnet synchronous generator. The reactive power required for the operation of permanent magnet synchronous generator and grid is provided by STATCOM and equations for the system shown in Figure 2.1 is given by,

$$
\begin{aligned}
& P_{s}=V_{i}^{2} g_{s}-V_{i} V_{s}\left(g_{s} \cos \left(\theta_{i}-\theta_{s}\right)+b_{s} \sin \left(\theta_{i}-\theta_{s}\right)\right) \\
& Q_{s}=-V_{i}^{2} b_{s}-V_{i} V_{s}\left(g_{s} \sin \left(\theta_{i}-\theta_{s}\right)-b_{s} \cos \left(\theta_{i}-\theta_{s}\right)\right)
\end{aligned}
$$

Shunt compensators are primarily used for bus voltage regulation by means of providing or absorbing reactive power; they are effective for damping electromechanical oscillations $[14,15]$. Different kinds of shunt compensators are currently being used in power systems, of which the most popular ones are Static Var Compensator SVC and STATCOM [16]. 
In this work, only the STATCOM, which has a more complicated topology than a SVC, is studied. The resulting STATCOM can inject or absorb reactive power to or from the bus to which it is connected and thus regulate bus voltage magnitudes [16]. The main advantage of a STATCOM over a SVC is its reduced size, which results from the elimination of ac capacitor banks and reactors; moreover, a STATCOM response is about 10 times faster than that of a SVC due to its turn-on and turn-off capabilities. Figure 2 illustrate a single-line diagram of the STATCOM and a simplified block diagram of its control system.

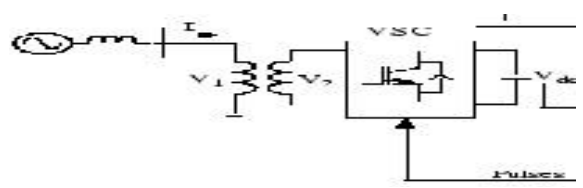

Figure 2. STATCOM Connection

The control system of STATCOM consists of:

1. A phase-locked loop (PLL) which synchronizes on the positive-sequence component of the three-phase primary voltage V1. The output of the PLL (angle $\theta=t$ ) is used to compute the direct-axis and quadrature-axis components of the $A C$ three-phase voltage and currents (labelled as Vd, Vq or Id, lq on the diagram).

2. Measurement systems measuring the $d$ and $q$ components of $A C$ positive-sequence voltage and currents to be controlled as well as the DC voltage Vdc.

3. An outer regulation loop consisting of an $A C$ voltage regulator and a DC voltage regulator. The output of the $A C$ voltage regulator is the reference current lqref for the current regulator ( $\mathrm{lq}=$ current in quadrature with voltage which controls reactive power flow). The output of the DC voltage regulator is the reference current Idref for the current regulator (Id = current in phase with voltage which controls active power flow). Figure 3, and Figure 4 have shown the $A C$ voltage regulator and the DC voltage regulator respectively.

4. An inner current regulation loop consisting of a current regulator. The current regulator controls the magnitude and phase of the voltage generated by the converter $(\mathrm{Vd} \mathrm{Vq})$ from the Idref and lqref reference currents produced respectively by the DC voltage regulator and the $A C$ voltage regulator (in voltage control mode). The current regulator is assisted by a feed forward type regulator which predicts the V2 voltage output (V2d V2q) from the V1 measurement ( $1 \mathrm{~d} \mathrm{~V} 1 \mathrm{q})$ and the transformer leakage reactance.

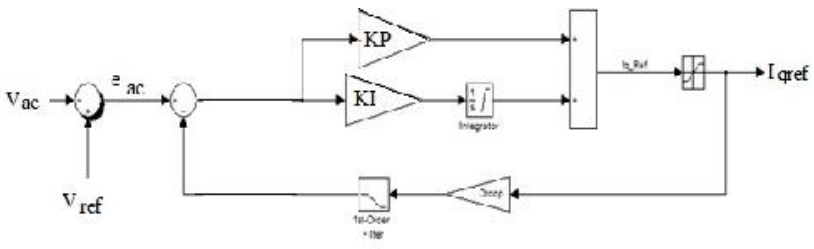

Figure 3. AC voltage regulator

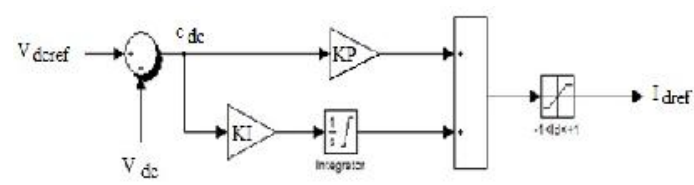

Figure 4. DC voltage regulator

The STATCOM controller in on wind system consists of two controllers, firstly: in AC voltage regulator, secondly: in DC voltage regulator. Errors in system are: 


$$
\begin{aligned}
& e=e_{a c}+e_{d c} \\
& e_{a c}=V_{r e f}-V_{a c} \\
& e_{d c}=V_{r e f}-V_{d v}
\end{aligned}
$$

Figure 5 shows the schematic PI Controller in STATCOM with wind system.

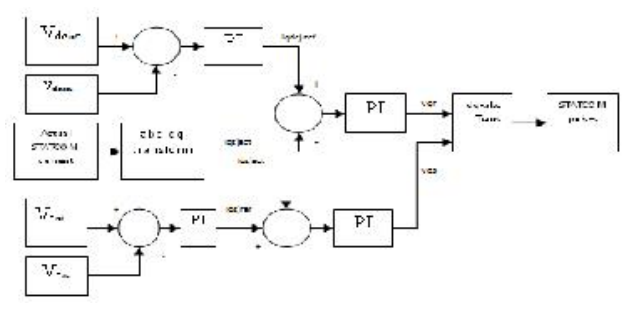

Figure 5. PI Controller in STATCOM

\section{Fuzzy Logic Controller and ANFIS Controllers}

The Voltage controller determines the value of the leading voltage should be injected to the grid bus to compensate the inverter voltage. The compensated voltage can be adjusted by changing the firing angle of the STATCOM compensator IGBTS. The output signal of the fuzzy controller, $\mathrm{Vc}$, is used to determine the suitable firing angle of the compensator IGBTS. To compensate high voltage to the grid bus the controlling voltage, $\mathrm{Vc}$, should be increased, and Vic versa.

The error of the Voltage of the inverter and the rate of change of voltage error are calculated as following:

$$
\mathrm{Ve}=\text { Vref }- \text { Vinv }
$$

In this paper these error criteria will be minimized by applying an existing tuning algorithm through the application of a fuzzy logic controller, as will presently be elucidated for a comprehensive and introduction to fuzzy [17]. Considering the fuzzy controller shown in figure (4.12) there are several scaling gains are introduced to the proportional plus integral, and at the same time gain go between the fuzzy controller and the STATCOM. The dynamic behavior of the fuzzy controller (Figure 6) is highly dependent on these scaling factors. These factors have to be selected carefully in order to achieve good performance.

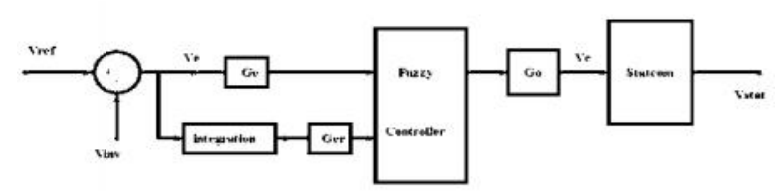

Figure 6. Fuzzy Controller for Voltage Stabilization

Voltage source converter (VSC) based STATCOM is developed with Adaptive Neuro Fuzzy Inference System (ANFIS) controllers. ANFIS controller requires less computation time and characteristics of both fuzzy and neuron controllers. The ANFIS has the ability to generalize and can interpolate in between the training data as well as the membership function has been decided according to the training data. 
The difference between $A C$ voltage measured and reference $A C$ voltage reference is input to ANFIS1 gives an error signal one e1(t), also the difference between DC voltage measured and reference DC voltage reference is input to ANFIS2 gives an error signal two e2(t) as shown in Figure 7. First of two input signals of ANFIS is the error signal e(t), the second one is the changing of error signal depending on time $\mathrm{de}(\mathrm{t}) / \mathrm{dt}$ and is expressed with correlations as:

$$
\begin{aligned}
& e_{1}(t)=V_{A C}-V_{A C r e f} \\
& e_{2}(t)=V_{D C}-V_{D C \text { ref }}
\end{aligned}
$$

The output signal of controller element is the value of voltage $\left(v_{2 d}, v_{2 q}\right)$. The output of ANFIS is entering to current regulation of STATCOM.

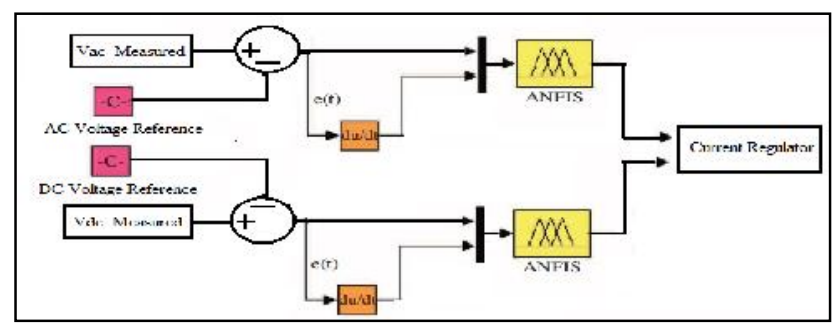

Figure 7. Simulation Block Diagram of STATCOM Controller with ANFIS

\section{Simulation Results}

5.1. Simulation of The proposed System without STATCOM

In this case, the dynamic response of the wind will be studied at a different step change in reference wind speed.

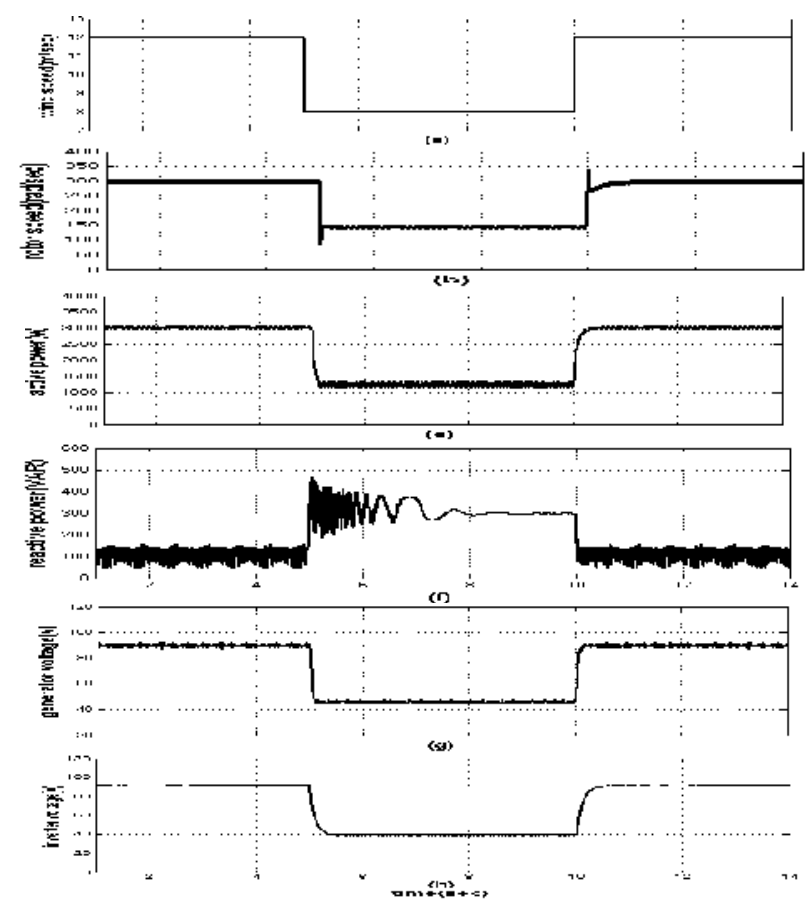

Figure 8. Open loop wind system for a small step change in wind speed 

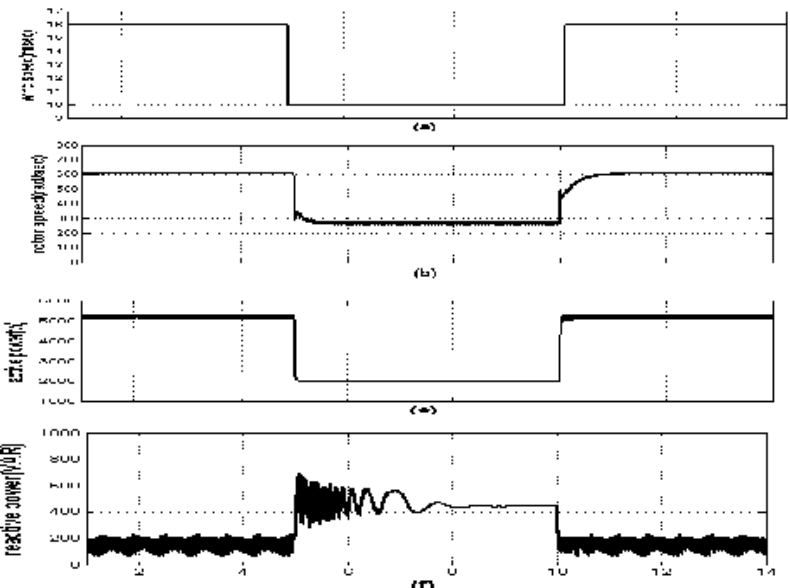

(n)

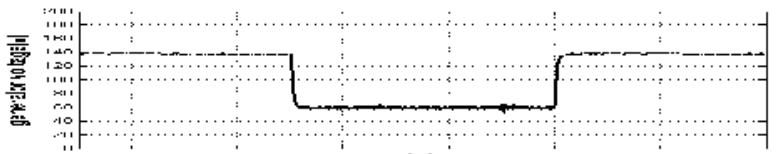

(ब)

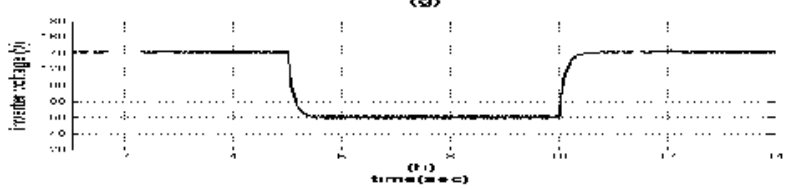

Figure 9. Open loop for large step change in wind speed

From Figure 8 and Figure 9 it can be noticed that increase in the wind turbine speed from small step change to large step change, the rotor speed increasing with increase the wind speed. The active power increases with the wind speed. As the same the inverter voltage increases with large step.

\subsection{Simulation Results of the Proposed System with STATCOM and PI Controller}

The voltage at the generator terminals is monitored to check whether the system has recovered. The generator speed is monitored to detect if the generator goes into over speed.

The dynamic response of the wind will be studied at a step change in reference wind speed. The proportional plus integral controller is the simple type of controllers that could be applied to the system. The controller gains are fixed and designed using trial and error at a certain operating condition.

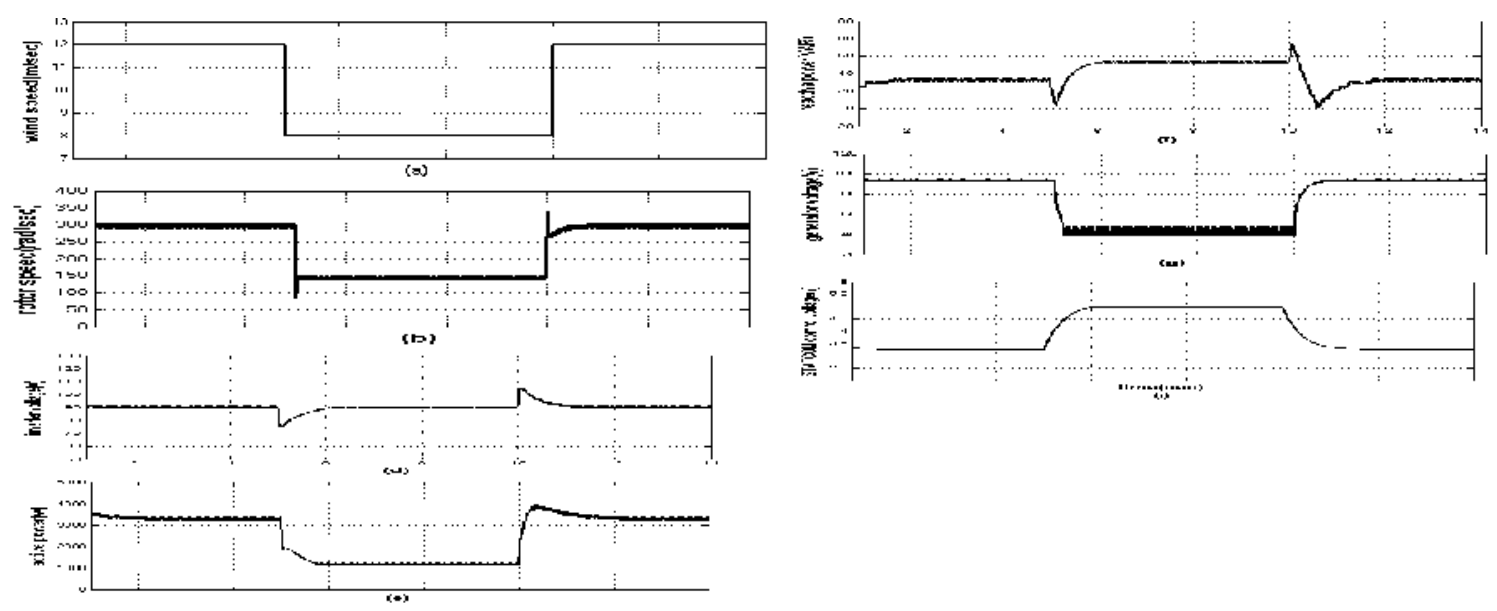

Figure 10. Simulation results of the proposed system with PI controller at small step change in wind speed 

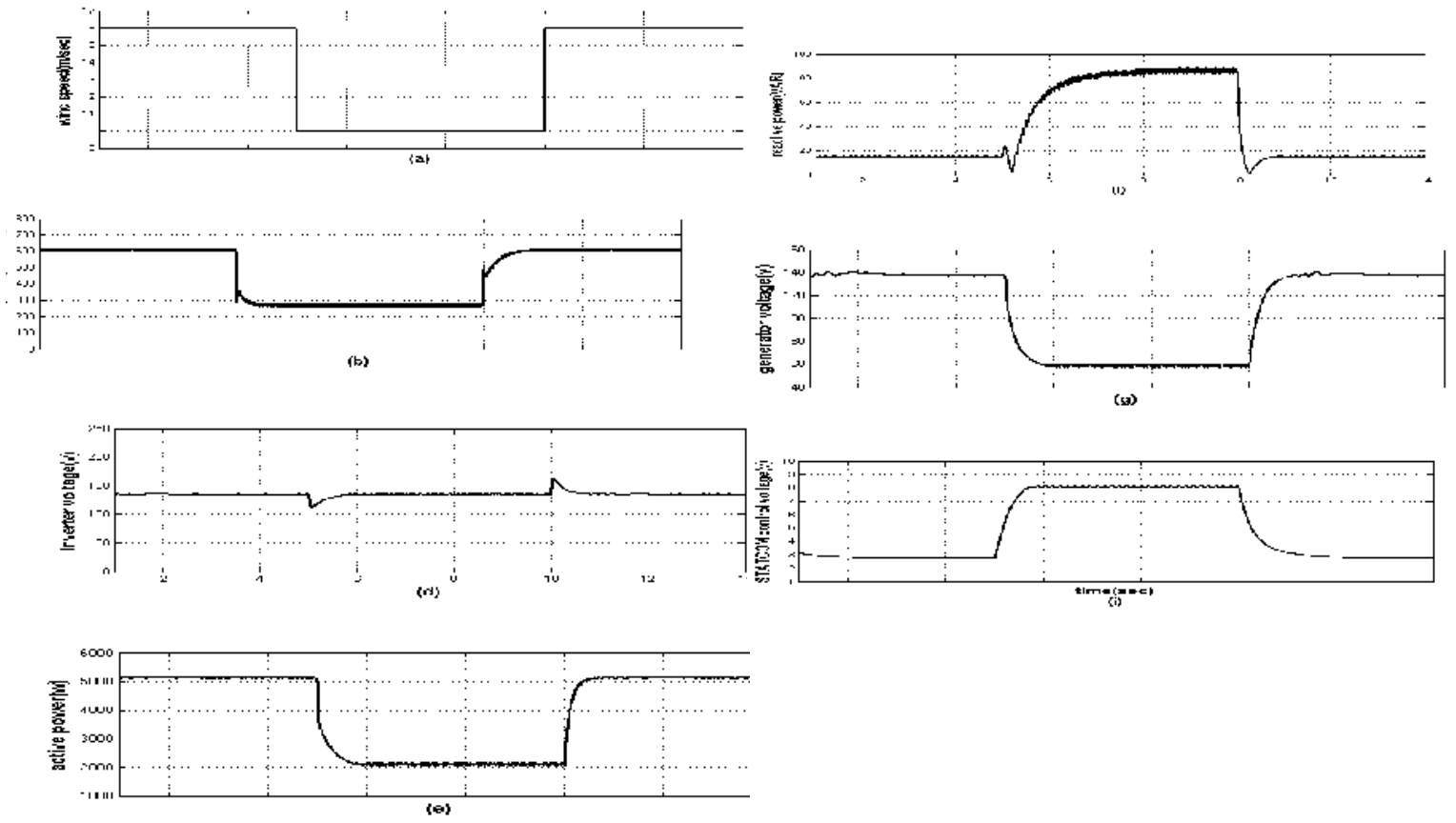

Figure 11. Simulation results of the proposed system at large step change in wind speed using $\mathrm{PI}$ controller

\subsection{Modelling of the Proposed System with STATCOM and FLC Controller}

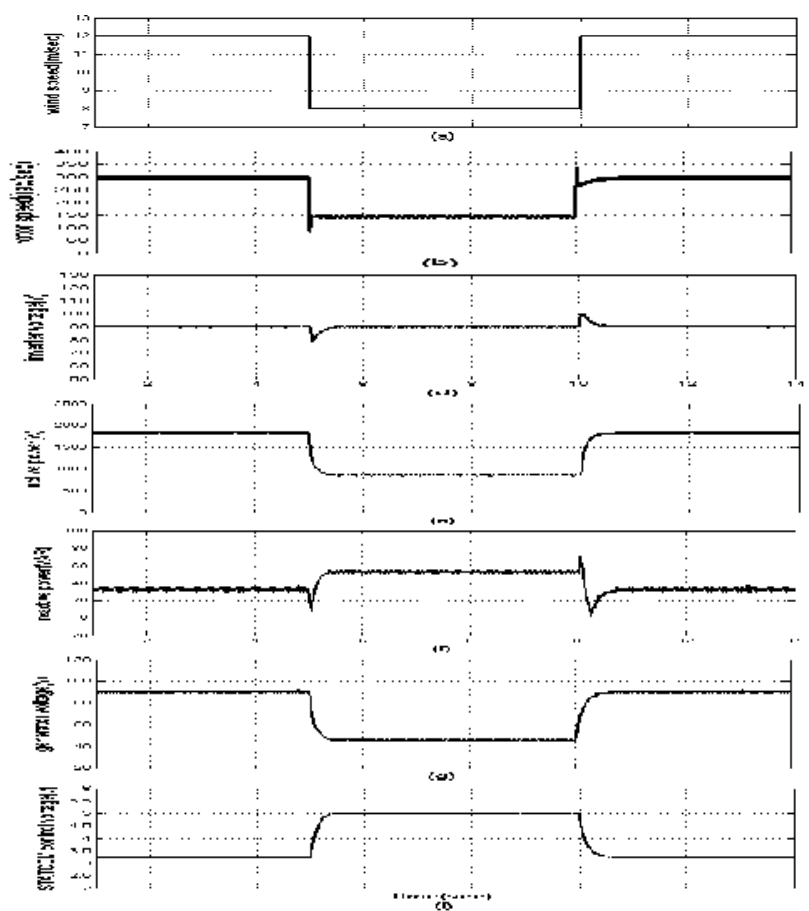

Figure 13. Simulation results of the proposed system at small step change in wind speed using FLC 

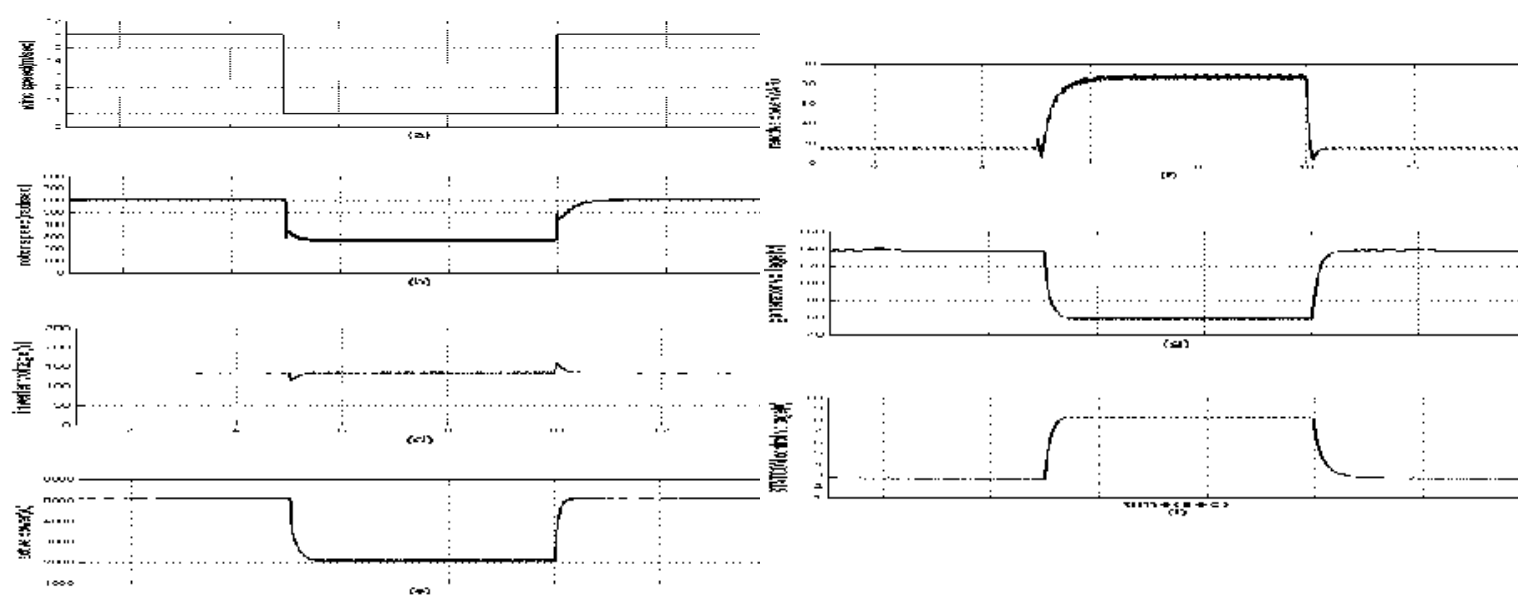

Figure 13. Simulation results of the proposed system at high step change in wind speed using FLC

The dynamic behaviour of the fuzzy controller is highly dependent on these scaling factors. These factors had selected carefully in order to achieve good performance for both steady state and transient conditions. In the above two figures small and large wind speed are more stable than proportional plus integral testes

\subsection{Modelling of the Proposed System with STATCOM and ANFIS Controller}

ANFIS is an adaptive network. An adaptive network is network of nodes and directional links. Associated with the network is a learning rule - for example back propagation. It's called adaptive because some, or all, of the nodes have parameters which affect the output of the node. [100] these networks are learning a relationship between inputs and outputs. Adaptive networks cover a number of different approaches but for our purposes we will investigate in some detail the method proposed by Jang known as ANFIS.
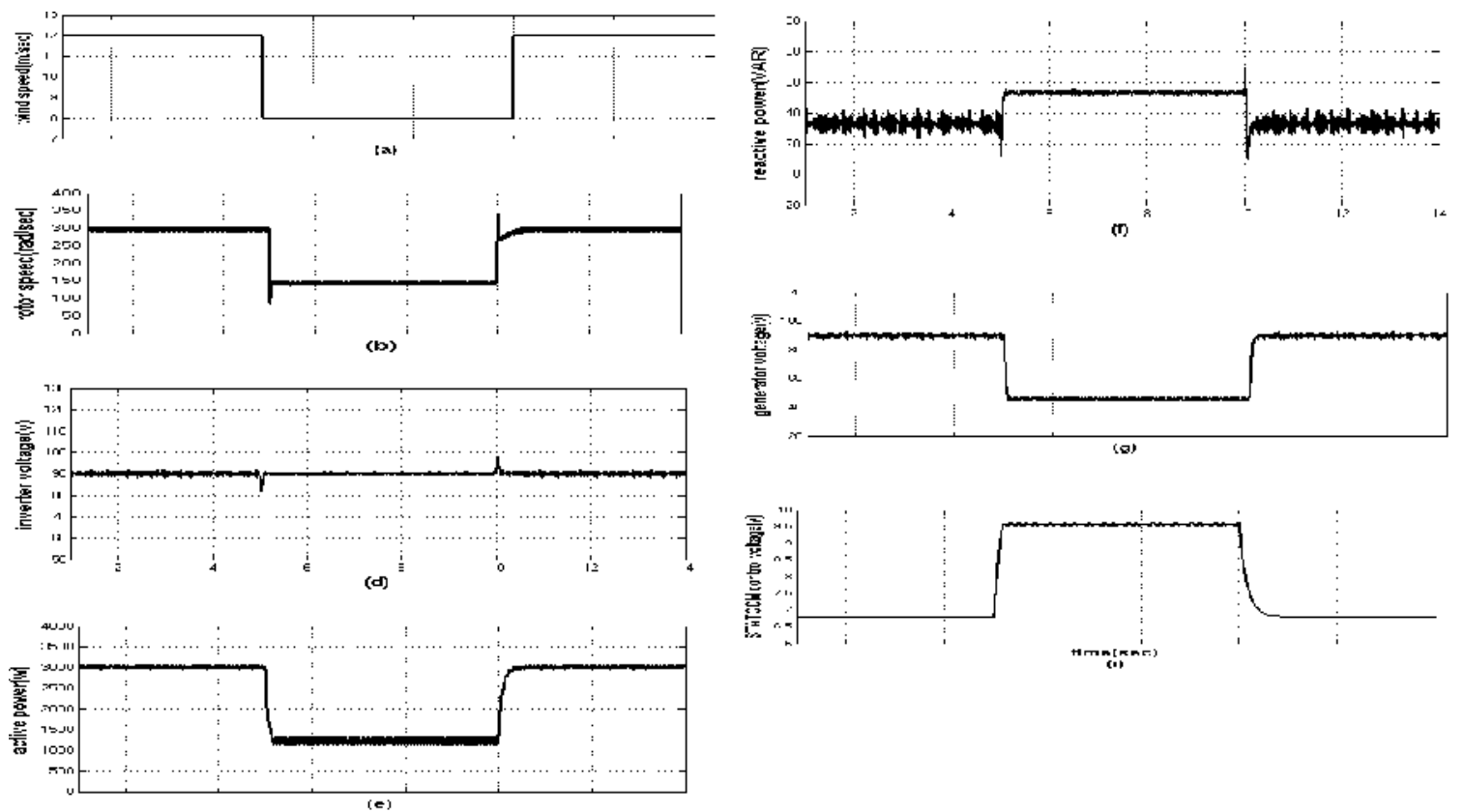

Figure 14. Simulation results of the proposed system at small step change in wind speed using ANFIS 

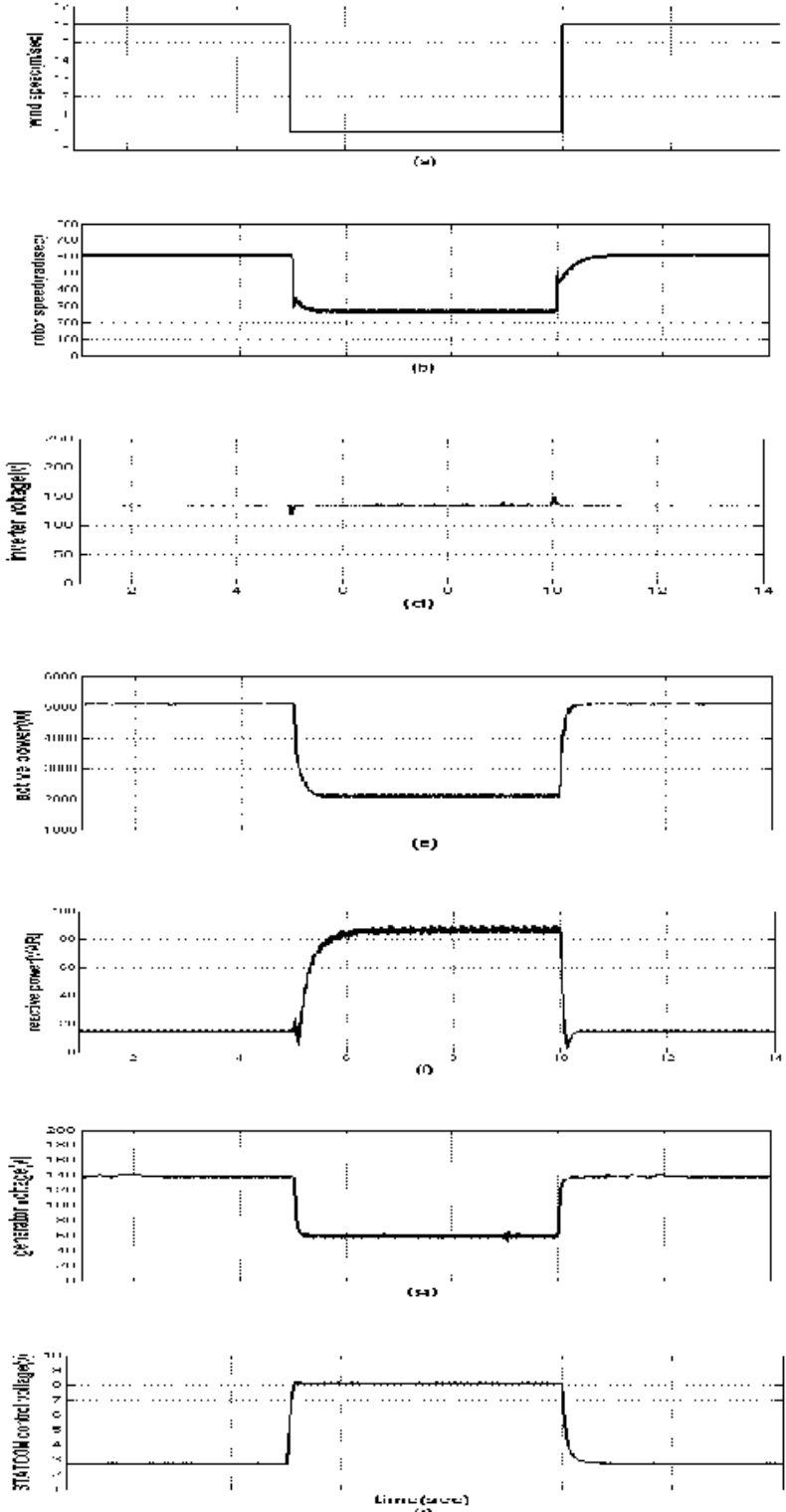

Figure 15. Simulation results of the proposed system at high step change in wind speed using ANFIS

\section{Comparison between Conventional and Intelligent Control}

Figure 16 shows the comparison between the ANFIS controller, fuzzy logic controller and proportional plus integral controller. The gains of the proportional plus integral are $\mathrm{Kp}=5$, and $\mathrm{Ki}=0.00851$ give the best performance of the regulate system with PI controller. Both controllers are tested with the same constraints and the operating conditions. 

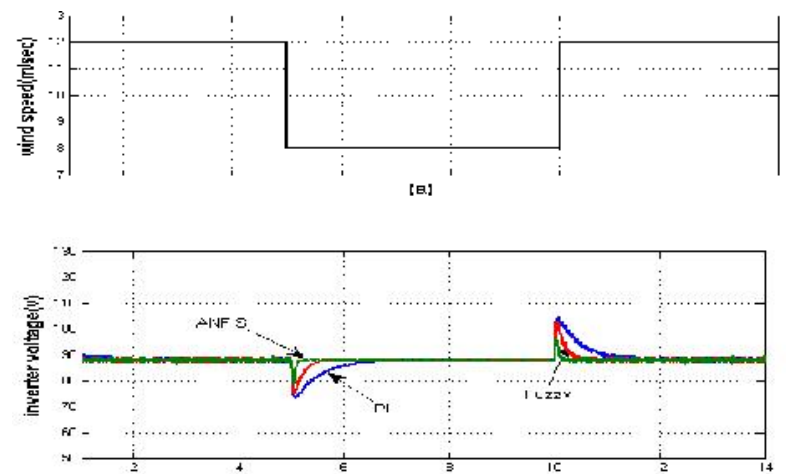

(b)

Figure 16. Comparison of PI, fuzzy, and ANFIS controllers at small step change in wind speed

For a large step in wind speed, Figure 17 shows the system performance by with $\mathrm{PI}$ controller and intelligent controllers. ANFIS controller is the best controller where the voltage response of the wind system is fastest and least steady-state error.
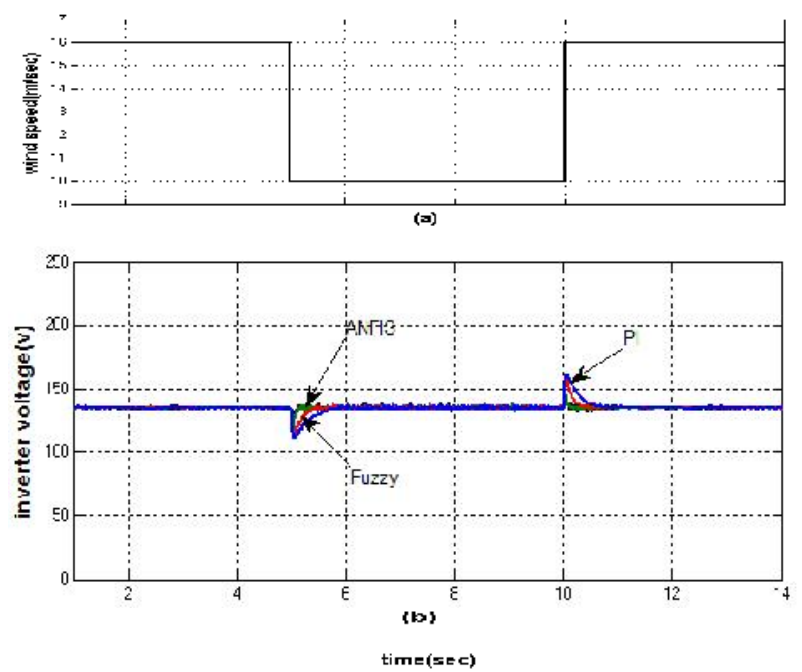

Figure 17. Comparison of PI, fuzzy, and ANFIS controllers at large step change in wind speed

\section{Conclusion}

This paper concerned with solution of the voltage problems of the wind energy system. Several techniques are proposed to regulate the output voltage of the wind system. Digital controller is developed such as proportional plus integral, ANFIS and fuzzy logic to achieve the best performance of the STATCOM. Wide range of operating conditions of wind speed was considered in this paper to achieve the most suitable controlling technique.

Mathematical models were used to achieve linear models of all the system, as wind turbine model, rectifier model, DC-link model, inverter model, grid model, and STATCOM model

With STATCOM controller the voltage of the inverter was independent of the winds speed. That means, the STATCOM was fully regulated to achieve a constant inverter voltage independent the wind speed variations.

The intelligent controllers (FLC, ANFIS) are better than the conventional PI controller, where the wind system performance is faster and less steady-state error. 


\section{References}

[1] Ackermann T. "Wind Power in Power Systems". John Wiley \& Sons. 2005.

[2] Hunter REG. "Wind-diesel systems a guide to technology and its implementation". Cambridge University Press. 1994.

[3] Lipman NH. "Wind-diesel and autonomous energy systems". Elservier Science Publishers Ltd. 1989.

[4] Bhatti TS, Al-Ademi AAF \& Bansal NK. "Load frequency control of isolated wind diesel hybrid power systems". International Journal of Energy Conversion and Management. 1997; 39: 829-837.

[5] Das D, Aditya SK \& Kothari DP. "Dynamics of diesel and wind turbine generators on an isolated power system". International Journal of Elect Power \& Energy Syst. 1999; 21: 183-189.

[6] NG Hingorani and L Gyugyi. "Understanding FACTS: Concepts and Technology of Flexible AC Transmission Systems". IEEE, New York, ISBN 0-7803. 2000: 3455-3458.

[7] JB Park, KS Lee, JR Shin and KY Lee. "A particle swarm optimization for economic dispatch with nonsmooth cost functions". IEEE Trans. on Power Systems. 2005; 20(1): 34-42.

[8] Hamesh babu Nanvala, Gajanan K Awari. "Review on use of Swarm Intelligence Meta heuristics in Scheduling of FMS". International Journal of Engineering and Technology (IJET). 2011; 3(2): 80 - 86.

[9] $\mathrm{H}$ Mori and $\mathrm{Y}$ Goto. "A parallel tabu search based method for determining optimal allocation of FACTS in power systems". Proc. Of the International Conference on Power System Technology (PowerCon 2000). 2000; 2: 1077-1082.

[10] W Ongsakul and P Jirapong. "Optimal allocation of FACTS devices to enhance total transfer capability using evolutionary programming". Proc. of the IEEE International Symposium on Circuits and Systems (ISCAS 2005). 2005; 5: 4175-4178.

[11] LJ Cai, I Erlich and G Stamtsis. "Optimal choice and allocation of FACTS devices in deregulated electricity market using genetic algorithms". Proc. of the IEEE PES Power Systems Conference and Exposition. 2004; 1: 201-207.

[12] S Gerbex, R Cherkaoui and AJ Germond. "Optimal location of multitype FACTS devices in a power system by means of genetic algorithms". IEEE Trans. on Power Systems. 2001: 16(3): 537-544.

[13] Wind/Diesel Systems Architecture Guidebook. AWEA. 1991.

[14] Siegfried Heier. "Grid integration of wind energy conversion systems". Jon Wiley \& Sons Ltd. 1998.

[15] E Uzunovic. "Transient Stability and Power Flow Models of VSC FACTS controllers". Ph.D. dissertation, University of Waterloo, Waterloo, ON, Canada. 2001

[16] Sim Power Systems User guide. Available http://www.mathworks.com.

[17] Davis and Lawrence. "Handbook of Genetic Algorithms". Van Nostrand Reinhold, 115 Fifth Avenue, New York, NY 10003. 1991. 